\title{
Iatrogenic Factors Affecting the Periodontium: An Overview
}

\author{
Ravi Varma Prasad ${ }^{1, *}$, Siddharth Chincholi ${ }^{2}$, Deepika $V^{1}$, Syed Sirajuddin ${ }^{3}$, Shriparna Biswas ${ }^{3}$, \\ Sandeep S. Prabhu ${ }^{3}$ and Rakesh MP
}

${ }^{I}$ Department of Periodontology, MNR Dental College \& Hospital, Sangareddy, Telangana State, India; ${ }^{2}$ Department of Periodontology, HKDET Dental College \& Hospital, Humnabad, Karnataka, India; ${ }^{3}$ Department of Periodontology, Rajarajeswari Dental College \& Hospital, Bangalore-560074, Karnataka, India

\begin{abstract}
The principal reason of gingival inflammation is bacterial plaque, along with other predisposing factors. These predisposing factors are calculus, malocclusion, faulty restorations, complications associated with orthodontic therapy, self- inflicted injuries, use of tobacco \& radiation therapy. The contributing factors to gingival inflammation $\&$ periodontal destruction are deficient dental restorations and prosthesis. Inadequate dental procedures that add to the weakening of the periodontal tissues are referred to as iatrogenic factors.
\end{abstract}

Keywords: Bacteria, calculus, iatrogenic damage, inflammation, plaque, radiation therapy, restoration.

\section{INTRODUCTION}

"An Ounce of Prevention worth a Pound of Cure"

"Iatrogenic" Comes from the Greek Language. "Iatros" Means Doctor or Healer. "Gennan" Means "as a Result".

Iatrogenesis or iatrogenic effect, ("originating from a physician") is avoidable harm ensuing from medical treatment or advice to patients. Physicians, pharmacists, nurses, dentists, psychiatrists, psychologists, and therapists are the professionals who may sometimes cause harm to the patients. Iatrogenesis can also result from corresponding and alternative medicine treatments.

Iatrogenesis is a very common, often preventable, hazard of treatment and is related with considerably increased patient mortality and cost [1].

Since the time of Hippocrates people have accepted the possible damaging effects of a healer's actions.

A tradition of conservatism in medical practice has understandably grown up in the centuries since Hippocrates admonished his disciples, "Primum non nocere" (first, do no harm). Man also has long been aware of the hazards of the doctor-patient relationship, as well as the benefits. Napoleon, when advised to consult his physician, allegedly declaimed, "I do not want two diseases - one nature-made, one doctormade", and marched off instead to Russia [2].

The amount of preventable adverse events remains startlingly high because very less improvement of iatrogenic complications has been made in spite of early recognition of the problem and better care and prophylaxis.

One should not, however, assume that iatrogenic disorders always stem from malpractice, or poor practice. In many

*Address correspondence to this author at the Department of Periodontics, MNR Dental College and Hospital, Sangareddy. Telangana State, India; Tel: 09885790777; E-mail: anjinidental@gmail.com instances they are unavoidable consequences of treatment; in other instances, they are unforeseen, or unforeseeable, consequences of treatment.

\section{DEFINITION}

Iatrogenic injury is a comprehensive term that may be defined as 'harm, hurt, damage or impairment that results from the activities of a doctor' [3]. Iatrogenic injury produced by either an inadvertent or erroneous treatment, or may be a result of either act of commission or act of omission by the therapist [4]. Dental iatrogenic treatment can produce injury either on the tooth or the Periodontium or both.

Iatrogenic trauma can be defined as any trauma that has been induced by the dentist's activity, manner, or therapy, and this term is generally used for an infection or other complications of treatment. During dental and periodontal treatments, various instruments (i.e., rotary or vibratinghand pieces, electrosurgical units, and lasers), chemical substances (i.e., drugs, endodontic materials and retraction agents), and physical appliances (partial dentures and orthodontic appliances) come in contact with the oral cavity, and inappropriate use or application of these may result in traumatic gingival lesions [5]. The etiology of periodontal disease can be iatrogenic in nature. Diagnostic procedures, Restorations, Endodontic therapy, Fixed and removable prosthesis, Orthodontic therapy and Oral and maxillofacial surgical procedures have the potential to become iatrogenic to periodontal structures if not carried out properly. An improperly prepared tooth may have an adverse effect on long-term dental health. For example, insufficient axial reduction inevitably results in an over contoured restoration that hampers plaque control. This may cause periodontal disease [6].

The foundation for proper esthetics, function, and comfort to the dentition is provided by the periodontal tissues. All prosthetic and restorative therapies largely need a healthy periodontium as a prerequisite for successful treatment. The 
relationship and interaction between periodontics and restorative dentistry is present at many fronts, including location of restorative margins, crown contours, and response of the gingival tissues to restorative preparations. Therelationship of iatrogenic factors with periodontal breakdown was originally recognized in 1912 by BlackA [7].

The association between dental restorations and periodontal health and has been carefully investigated for many years. Studies have concentrated their attention on various aspects of the periodontal- restorative interaction, such as position of the restoration with respect to the gingival margin, presence of overhangs, presence of marginal leakage, roughness of the surfaces, and the type of restorative material [8].

Prior to any dental procedure, with the exception of treatment of acute carious lesions that involve or threaten the health of the pulp, existing pathologic condition must be recognized and treated to set up a healthy environment. Restoring the periodontium to health is the basic necessity prior to other dental therapy. This includes the removal of gingival irritants, correction of functional andocclusal interferences, treatment of morphologic and pathologic gingival conditions, and corrections of bony deformities of the supporting periodontium.

\section{CONCLUSION}

The expertise, familiarity, and up-to-date knowledge of dentist are the foremostreasons to avert possible iatrogenic traumas. Although "To err is human," careful practice is very important for the principle "Primum non nocere" ("First do no harm").

\section{CONFLICT OF INTEREST}

The authors confirm that this article content has no conflict of interest.

\section{ACKNOWLEDGEMENTS}

Declared none.

\section{REFERENCES}

[1] www.professionalpracticegroup.net/powerpoints/iatrogenesis.ppt Oct 22, 2009.

[2] Wolf JA, Hanson H, Moir MJ, Friedman L, Savage GT, Eds. Organization Development in Healthcare: Conversations on Research and Strategies. Advances in Health Care Management Series \#10. Emerald Group Pub 2011; p. 292.

[3] AAP: Glossary of Periodontal Terms: $4^{\text {th }}$ ed: Chicago: American Academy of Periodontology 2001.

[4] Vandersall DC. problems and dangers of adult tooth movement in general dentistry. In: Schlossberg A, Ed. Philadelphia: Saunders 1975; p. 195.

[5] Rawal SY, Claman LJ, Kalmar JR, Tatakis DN. Traumatic lesions of the gingiva: A case series. J Periodontol 2004; 75: 762-9.

[6] Sorensen JA: a rationale for comparison of plaque-retaining properties of crown systems. J Prosthet Dent 1989; 62: p. 264.

[7] Black A. Preventive treatment of periodontal diseases. Northwestern Dental J 1912; 10: 60-73.

[8] Waerhaug J. Effect of rough surfaces upon gingival tissue. J Dent Res 1956; 35: 323-5.

Received: December 22, 2014

Revised: March 04,2015

Accepted: March 10,2015

(C) Prasad et al.; Licensee Bentham Open

This is an open access article licensed under the terms of the Creative Commons Attribution Non-Commercial License (http://creativecommons.org/licenses/by-nc/3.0/) which permits unrestricted, non-commercial use, distribution and reproduction in any medium, provided the work is properly cited. 